OPEN ACCESS (C) (1) (2)

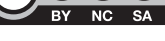

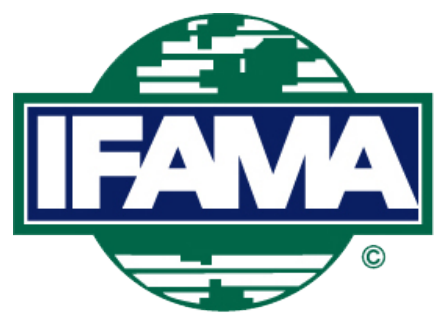

International Food and Agribusiness Management Review

Volume 23, Issue 4, 2020; DOI: 10.22434/IFAMR2019.0125

Received: 6 August 2019/ Accepted: 30 April 2020

\title{
Food expenditures and consumption by food bank clients in Silicon Valley \\ RESEARCH ARTICLE
}

\author{
Courtney N. Robinson ${ }^{\mathrm{a}}$, Gregory A. Baker ${ }^{\circledR b}$, Michael J. Harwood ${ }^{\mathrm{c}}$ and Lucy O. Diekmann ${ }^{\mathrm{d}}$ \\ ${ }^{a}$ Former Research Assistant, ${ }^{b}$ Executive Director, ${ }^{c}$ Former Professor of Practice,

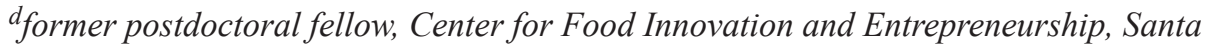 \\ Clara University, 500 El Camino Real, Santa Clara, CA 95053-0396, USA
}

\begin{abstract}
Food insecurity is a pervasive problem in the United States and it is particularly acute in high cost areas. This study focuses on the diets and food expenditures of food bank clients in two Northern California counties located in what is commonly known as Silicon Valley. The results indicate that the study group spent 27\% more than the federal government's Thrifty Food Plan, but consumed a lower amount of fruits, vegetables, protein, and dairy than what is needed for a healthy diet. Policies that encourage better nutrition and more balanced diets at affordable prices and which take into account the living and transportation situations of food insecure populations are needed to address these issues.
\end{abstract}

Keywords: food insecurity, hunger, nutrition, food assistance JEL code: I30

\footnotetext{
(1) Corresponding author: gbaker@scu.edu
} 


\section{Introduction}

Food insecurity is a persistent problem in the United States. Defined as insufficient or uncertain "access to enough food for active, healthy living," food insecurity currently affects $11.8 \%$ of American households or roughly 40.0 million people, based on data for 2017, the most current government report (Coleman-Jensen et al., 2018). Households that lack the resources to obtain adequate food compromise their dietary intake by reducing the quality, variety or desirability of their diet, or in more dire circumstances, by eating less (USDA ERS, 2017). Obtaining a healthy diet at a low cost is particularly challenging because nutritious foods typically cost more than energy-dense, but nutrient-poor food options (Drewnowski and Eichelsdoerfer, 2010; Townsend et al., 2009). Thus, for many low-income Americans, "access to healthy foods at a reasonable price is a challenge that often places a strain on already limited resources and may compel them to make food choices that are contrary to current nutritional guidance" (IOM/NRC, 2013). These challenges may be amplified in high-cost locales where high cost of housing, transportation, and food further strain limited budgets. To understand how low-income individuals respond in these circumstances, this study examines the actual food costs and consumption patterns of food bank clients in Silicon Valley, one of the highest-cost regions in the United States.

Households that struggle to put food on the table can receive help from both federal and private food assistance programs. These programs aim to alleviate food insecurity and to increase the nutritional quality of participants' diets (Bomkamp, 2016; IOM/NRC, 2013). According to the most recent national assessment, $59 \%$ of food insecure households participated in one or more of the major federal food assistance programs: Supplemental Nutrition Assistance Program (SNAP), the Special Supplemental Program for Women, Infants, and Children (WIC), and the National School Lunch Program (Oliveira, 2018). SNAP, formerly known as food stamps, provided 42 million people with \$63.6 billion in benefits in 2017 (USDA FNS, 2018). When community needs are not met by public assistance, food banks step in to fill the gap (Bazerghi et al., 2016). For SNAP recipients whose benefits run out before the end of the month (Wiig and Smith, 2009) as well as for the $27 \%$ of food insecure households that do not qualify for federal assistance (Feeding America, 2014), charitable food assistance is an important, and, sometimes, the only, source of support. Feeding America (2014), the anti-hunger organization representing $80 \%$ of U.S. food banks, provides food to an estimated 46.5 million unique clients annually. Although charitable food assistance is meant to be short-term, more and more people are seeking food banks' services repeatedly throughout the year (Bazerghi et al., 2016).

The Thrifty Food Plan (TFP) serves as a national standard for a nutritious diet that can be purchased at minimal cost and, as such, is the basis for determining the allotment of benefits to SNAP participants (Clawson et al., 2007). Although SNAP benefits are constant across states (except for Alaska and Hawaii), the way that states calculate eligibility and benefits differs from state to state. To determine this model-market basket of healthy, but low-cost foods, the TFP combines national average prices, consumption habits of low-income individuals, and the recommendations of the Dietary Guidelines for Americans (Clawson et al., 2007). The vast majority of TFP expenditures are allocated to grains; meat, poultry, fish, and eggs; dairy products; and fruits and vegetables. Roughly $8 \%$ is dedicated to other foods, such as oils, seasonings, sugar and sweets, and non-alcoholic beverages (Stewart and Blisard, 2006). Because SNAP benefits are intended to provide low-income households with the additional resources they need to purchase the TFP market basket, the value of benefits received each month is the difference between the household's TFP cost and 30\% of its net monthly income (Stewart and Blisard, 2006). Therefore, households with little or no income receive the maximum monthly SNAP allotment (i.e. the full TFP cost), while other households receive the TFP amount less $30 \%$ of their net income (IOM/NRC, 2013). Additionally, the TFP assumes that low-income families will prepare all their food at home and includes neither prepared foods nor foods consumed away from home.

The adequacy of the TFP as a means for meeting the goals of alleviating food insecurity and improving the nutritional quality of individuals' diets has been questioned by many researchers, (for example, Drewnowski and Eichelsdoerfer, 2010; IOM/NRC, 2013). In a recent study, Mulik and Haynes-Maslow (2017) found that "the current levels of SNAP benefits plus expected personal expenditures" fell substantially short of 
covering the full cost of a healthy diet as recommended by MyPlate by as much as $\$ 627$ per month for a family of four. Similarly, Bronchetti et al. (2016) estimate that SNAP benefits and 30\% of household income are sufficient for only 20 to $30 \%$ of households receiving SNAP benefits to purchase the TFP.

Other researchers have questioned the approach of basing SNAP payments on the TFP. Wilde and Llobrera (2009) note that the TFP cost target is obtainable only with a very large modification in current consumption standards or by using nutrition standards instead of the MyPyramid food categories. Of course, nutrition standards are not easily imposed on households. Another criticism of using the TFP as a baseline is that it does not include the cost of labor to prepare food (Davis and You, 2010). They note that when labor costs are included, there is a disincentive to adhering to the TFP and associated food guidelines. This may explain why most households do not come close to meeting the TFP's dietary guidelines. Babb et al. (2019) provide a critique of the objective function utilized in calculating the TFP. They argue that there other formulations that are "theoretically and computationally more straightforward, are easier to interpret, have improved goodness-of-fit to current consumption, and feature allocations that are not substantially sparser than the current model." Furthermore, choosing a different objective would make it easier to develop a nutritious diet that is closer to the current consumption patterns.

A variety of factors affect whether the TFP is adequate for meeting food-insecure households' needs (IOM/ NRC, 2013). These include a household's resources: both financial resources and available time. But resources alone do not determine a household's access to healthy food. Household characteristics and environmental factors intersect to determine whether a fixed level of resources is sufficient to procure affordable and healthy food (IOM/NRC, 2013). Household characteristics include the personal and cultural taste preferences of its members as well as special dietary needs along with the skills, space, and equipment to prepare foods from scratch (IOM/NRC, 2013). Environmental factors affecting the ability to access food include physical access to transportation and proximity to healthy and affordable food outlets as well as financial access, which is shaped by gasoline prices, food prices, and the cost of other household goods. Qualitative studies of lowincome families have shown that food expenditures can be adjusted to free up money for other necessities, but that there is relatively little flexibility in housing and utility costs (Kirkpatrick and Tarasuk, 2011).

The cost of living is a critical factor in determining whether available household income and SNAP benefits are sufficient to provide a nutritious diet. Bronchetti et al. (2016) write that "geographical variation in food prices may render SNAP benefit levels inadequate for a sizeable fraction of households to purchase the TFP, despite the fact that this bundle of foods provides the basis for legislated SNAP benefit levels." Considering the interplay of food prices, environmental factors, household characteristics, resources, and the cost of living on the ability to access healthy food options, we expect that low-income households in high-cost areas, like the San Francisco Bay Area, may be especially challenged in obtaining a healthy diet at an affordable price.

In this study we collect data on food bank clients' actual spending and consumption on food and compare it with the TFP's budget and consumption targets to determine to what extent their eating and spending patterns conform to the TFP's idealized allocation for a low-cost, healthy diet. The principal objectives of the study are:

- Estimate the actual expenditures on food items in the diets of food bank clients in a high cost region.

- Estimate the actual quantities of food items consumed in the diets of food bank clients in a high cost region.

- Compare the actual expenditures and quantities of food items consumed by food bank clients in a high cost region to the U.S. federal Thrifty Food Plan to assess the adequacy of food bank clients' diets and the extent to which the TFP budget is sufficient to meet their dietary needs.

- Develop recommendations for policy and food assistance organizations that reflect the realities of low-income food insecure individuals, and particularly those who live in high cost areas and who receive food assistance from food banks. 


\section{Methods}

\subsection{Study area}

This study took place in Santa Clara and San Mateo Counties, California, located in a larger region that is better known as Silicon Valley, one of the highest-cost living areas in the U.S. In 2018, a family of four living in Santa Clara County was considered low-income if they earned \$94,450 or less annually; in San Mateo County a family of four was considered low income if they earned $\$ 117,400$ or less annually (HUD, 2018). Paradoxically, the prosperity associated with Silicon Valley poses a unique set of challenges for low-income people. As the high-tech economy has grown, the cost of living, and especially housing, has increased, but wages for the majority of workers have not kept pace. Between 2006 and 2011, the median rent rose by 45\% while the median income rose by just 14\% (Weber, 2017). Recently, Second Harvest Food Bank of Santa Clara and San Mateo Counties (SHFB), which provides food to approximately 257,000 people each month, estimated that 720,000 people in the region were at risk of hunger (Simmonds, 2017). Research in Silicon Valley may highlight the challenges faced by low-income households in some of the country's other highcost metropolitan areas, such as Los Angeles, Seattle, Boston, New York, and Washington, D.C.

\subsection{Data collection}

In this research, we chose to focus on a targeted population of food bank clients. This differs from other approaches such as that utilized by Page et al. (2019), who use nationally-representative data. While our approach does not lend itself to generalization on a national scale, it was chosen because of the deep insights we could gain by understanding the vulnerable population of food assistance recipients in one of the highest cost regions of the country.

Data for this study were collected through in-depth, structured interviews with clients of SHFB. Interviews took place over a three-year period from June of 2011 to June of 2014. They were conducted with individuals who were participating in SHFB's two largest food distribution programs, Family Harvest (FH) and Brown Bag (BB). Through the FH program, low-income families can receive three to four bags of groceries once a month at 48 sites throughout Santa Clara and San Mateo Counties. To be eligible for the FH program, families must have a child under the age of 26 and be at or below $200 \%$ of the federal poverty level. The BB program serves senior citizens ( 60 years and older) and disabled seniors ( 55 years and older) who live in households that are at or below $200 \%$ of the federal poverty level. The BB program operates at 78 locations in Santa Clara and San Mateo Counties.

This study was developed in partnership with SHFB. Site visits for conducting interviews were arranged in advance with the cooperation of SHFB and the site administrator. In order to minimize distractions, interviews were only conducted at a site if there were no other external organizations conducting surveys on the day of the interview. During each site visit, researchers contacted everyone in line and interviewed all those who were willing to participate. On average, interviews lasted 10 to 15 minutes. The research team included translators who conducted interviews with Spanish and Vietnamese speakers as necessary. All interview subjects provided their informed consent under the Institutional Review Board protocol approved by the Santa Clara University's Office of Research Compliance and Integrity.

During the first year of the study, interviewers surveyed clients at a majority of the FH and BB sites. In the second and third years, interviewers concentrated on 25 sites based on the geographic distribution and size of the sites, as well as the ethnic diversity of the clientele. Larger sites were preferred as it was easier to complete interviews while the subjects were waiting in line without being interrupted when it was time for the interviewee to pick up his or her food. We attempted to achieve a balance in the respondents with respect to geography and ethnic diversity. 


\subsection{Interview protocol}

Interviews included a 24-hour dietary recall, in which participants were asked to describe all the foods and beverages they had consumed within the previous 24 hours. The 24-hour dietary recall protocol was developed based on recommendations from nutritionists at the Western Human Nutrition Research Center, Agricultural Research Service, USDA, in Davis, California and followed procedures recommended by Gibson (2005). Interviewers utilized measurement tools such as cups and bowls to help participants visualize the size of the portions they consumed. Individuals who are shown actual portion sizes are more likely to remember and report the accurate amount of food consumed (Godwin and Chambers, 2000). Participants were asked if the 24-hour dietary recall they provided was a good representation of their typical daily diet, and if not, how it differed. Researchers also collected information on demographics and asked participants which food items they would like to purchase more of if they had sufficient resources.

\subsection{Dietary analysis}

We used an on-line nutrition evaluation software program, Diet Analysis Plus 10.0, to calculate the nutritional composition of the foods reported by each subject and to derive an estimate of nutritional attainment. The software combines information about each participant (e.g. height, weight, age, gender, dietary restrictions, and fitness level) with USDA dietary requirements to calculate how much of each macronutrient and micronutrient each individual would need to maintain their current weight and fitness level. Once all foods that a subject reported consuming during the 24-hour recall period have been entered, the program calculates the sum of all dietary nutrient intakes and allows for the comparison to the individual's requirements for the day. This comparison revealed that the average participant underreported the amount of food consumed by $26 \%$. This degree of underreporting is comparable to that found in other studies that use a single-pass, 24-hour dietary recall method (Nestle, 2012). To correct for underreporting, we adjusted caloric intake upward or downward by proportionally increasing or decreasing the consumption of each listed food item to ensure that the overall food intake matched the expected caloric requirements. This adjusted figure is the basis for subsequent analyses of food consumption and expenditures.

To determine how the quantity of food in each category compared to TFP recommendations, we used Diet Analysis Plus 10.0 to convert the reported volume of food consumed to pounds of food consumed. Because the TFP provides the amount of food per category that should be consumed weekly, we multiplied pounds eaten in a day by seven to arrive at a weekly figure.

\subsection{Food cost calculations and analysis}

To estimate meal costs, researchers visited the grocery store where interviewees indicated that they purchased their groceries. These visits occurred within a week of the interview and a price for each food item reported as consumed by the interviewee was obtained. We believe that using price data obtained from the grocery store where each study participant shopped during the period when their purchases were made provides a more accurate representation of cost than the use of average national retail prices (Powers and Powers, 2001). The cost per serving was then calculated based on the price of each item and the amount consumed. For processed foods, the nutrition facts column was used to calculate the cost per serving. To determine how much an individual spent during the 24-hour period, we summed the actual cost for the quantity of each food item reported in the interview. Food prices were inflation-adjusted to 2014 dollars as were the TFP budget allocations.

We assigned a price to all reported food items as if they had been purchased - even though some items were purchased with SNAP benefits or received from SHFB - so our results represent the amount that purchasing that quantity and type of food would have cost, but may overestimate the amount actually spent on food if the participant was using some form of food assistance during the 24-hour recall period. However, only $29 \%$ of participants reported using SNAP or SHFB during the recall period. Of those receiving food assistance, a majority of recipients indicated that they received food from SHFB. 
To determine whether there were significant differences between what food bank clients spent and ate and the recommendations of the TFP, we conducted one-sample $t$-tests using the statistical program SPSS (IBM, Armonk, NY, USA).

\section{Results}

\subsection{Sample characteristics}

We surveyed a total of 802 food bank clients, 525 from the FH program and 277 from the BB program (Table 1). Only $18 \%$ of FH clients and $40 \%$ of BB clients reported that they participated in a federal food assistance program, such as SNAP or WIC. In keeping with FH and BB program eligibility requirements, all study participants belonged to households with incomes at or below $200 \%$ of the federal poverty level. In 2014 , the final year of data collection for this study, the income threshold for a family of four was $\$ 47,700$ (HHS, 2014).

We compared some of the available demographics from the American Community Survey with our sample population using statistics for people living below $125 \%$ of the poverty level, the closest level to the food bank's requirement for which data were available (U.S. Census Bureau, n.d.). It was not surprising to find that females were overrepresented in our sample, as this is typical at food banks across the U.S. (Feeding America, 2011). On the other hand, the racial/ethnic makeup of our sample closely mirrored that of the those living in poverty or the two-county area, with those identifying as Hispanic and Asian falling within $2 \%$ of the what is found for people living in poverty in the region. Our numbers for African American and non-Hispanic white representation in our sample were within 3 and 5\% of what was found in the two-county area, respectively.

\subsection{Food expenditures}

The average reported food expenditure for both programs was $\$ 5.28$ per person per day. Because there was no significant difference in food spending by FH and BB clients, we report the results of these two programs together. After adjusting for underreporting, as described in the Methods section, the average adjusted daily food cost was $\$ 6.87$ per person, $\$ 1.47$ (27\%) over the maximum SNAP allotment of $\$ 5.40$.

Table 1. Demographic information for study participants and people living in poverty in Santa Clara and San Mateo Counties.

\begin{tabular}{lllll}
\hline & $\begin{array}{l}\text { Family } \\
\text { harvest }\end{array}$ & Brown bag & Total sample & $\begin{array}{l}\text { People living in poverty } \\
\text { in two-county area }\end{array}$ \\
\hline Number of subjects & 525 & 277 & 802 & - \\
Average age & 40.3 & 64.3 & 48.6 & - \\
Female (\%) & 81.3 & 68.3 & 76.9 & 53.1 \\
Average BMI & 27.1 & 26.5 & 27.0 & - \\
Average exercise (hours/week) & 2.8 & 2.4 & 2.7 & - \\
\% born in the U.S. & 34.5 & 42.5 & 37.2 & - \\
Average years in U.S. if foreign born & 16.4 & 23.0 & 18.5 & - \\
\% receiving government food assistance & 17.7 & 40.3 & 32.5 & - \\
Hispanic (\%) & 59.0 & 23.1 & 46.6 & 47.7 \\
Asian (\%) & 18.5 & 38.6 & 25.4 & 23.6 \\
Non-Hispanic white (\%) & 12.0 & 24.5 & 16.3 & 21.1 \\
African American (\%) & 7.8 & 7.2 & 7.6 & 4.7 \\
\hline
\end{tabular}

${ }^{1}$ Demographic statistics for the two-county area of Santa Clara and San Mateo counties were based on data obtained from the American Community Survey (U.S. Census Bureau, n.d.) for 2014 for individuals below 125\% of the poverty level. 
Food bank clients spent $65 \%$ of their daily food expenditures on three food groups: protein, other foods, and vegetables (Figure 1). Compared to the TFP, food bank clients spent $14 \%$ more on grains, $74 \%$ more on protein, $285 \%$ more on other foods, and $46 \%$ less on dairy products than recommended (Table 2 ). These differences in spending were all statistically significant $(P \leq 0.001)$.

Further breakdowns of items within food groups provide a finer-grained analysis of what food bank clients are purchasing. For example, the majority of expenditures on grains were on non-whole grain bread, cereals, rice, and pasta, and nearly double what is recommended by the TFP (Table 2). For dairy, purchases of low-fat and skim milk and low-fat yogurt dairy products were $75 \%$ lower than TFP recommendations, although food bank clients still spent more on these items than any other type of dairy product. Within the protein group, the amount spent on eggs $(+1,042 \%)$, beef, pork, veal, lamb, and game $(+159 \%)$, fish and fish products (+94\%), and poultry $(+65 \%)$ were high relative to TFP recommendations, while purchases of nuts and seeds were low (-87\%). Finally, spending on other food items are higher than recommended for many subcategories, particularly for frozen or refrigerated entrees and soups.

\subsection{Consumption}

On average, food bank clients are eating 3.4 pounds less than the quantity of food in the TFP market basket each week (Table 3). Consumption of vegetables, dairy, fruit, and protein falls short of the TFP recommendations. However, consumption of grains and other foods are $91 \%$ and $305 \%$ higher than the TFP recommendations. The difference between TFP recommended and actual food consumption was significant for each category of food $(P \leq 0.001)$.

Paralleling spending patterns, consumption of grains is heavily weighted toward the non-whole grain category. Similarly, study participants spent less on low-fat and skim milk, and low-fat yogurt than suggested by the TFP. In the other food category, there are large differences between actual consumption and the TFP, which does not include allocations for frozen or refrigerated entries, soups, or soft drinks and fruit drinks, and includes only a, minimal allocation for coffee and tea.

Spending and consumption patterns were similar for the fruit, dairy, grains, and other food groups. For the fruit and dairy categories, food bank clients spent less and consumed less of both fruit and dairy products.
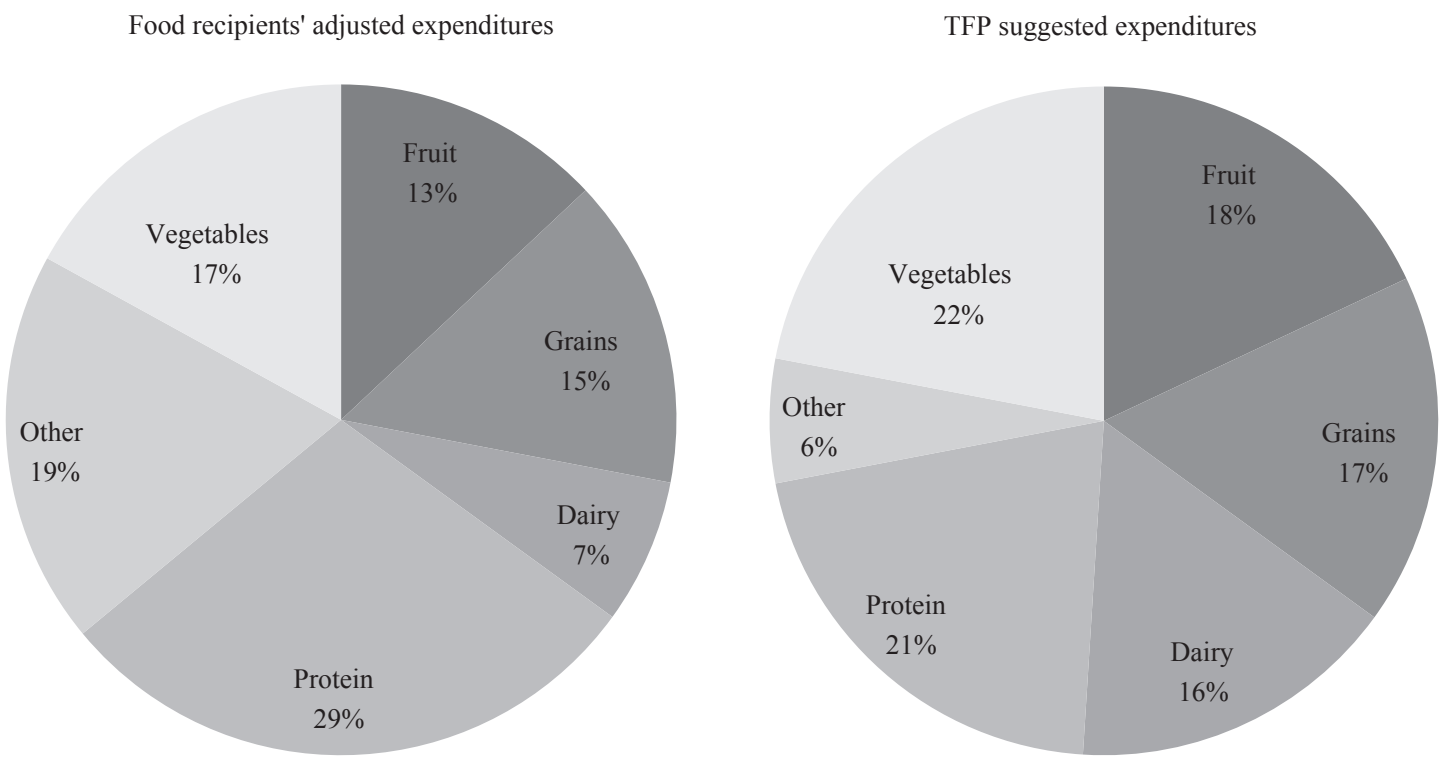

Figure 1. Food expenditure comparison, by major food categories, between the Thrifty Food Plan and lowincome food assistance recipients, Santa Clara and San Mateo Counties, CA, USA. 
Table 2. Budget allocation of sample for 6 different food categories, compared to the allocation that the USDA (TFP) suggests for their allocation of food stamp dollars. ${ }^{1}$

\begin{tabular}{|c|c|c|c|c|}
\hline Food category & $\begin{array}{l}\text { TFP cost / } \\
\text { category }(\$)\end{array}$ & $\begin{array}{l}\text { Adjusted cost / } \\
\text { category (\$) }\end{array}$ & $\begin{array}{l}\text { Difference between } \\
\text { actual cost and TFP, } \\
\text { as a } \% \text { of TFP }\end{array}$ & $P$-value \\
\hline Fruits & 6.86 & 6.26 & $-9 \%$ & 0.040 \\
\hline Whole fruits & 6.44 & 5.33 & $-17 \%$ & $\leq 0.001$ \\
\hline Fruit juices & 0.42 & 0.93 & $121 \%$ & $\leq 0.001$ \\
\hline Grains & 6.30 & 7.18 & $14 \%$ & $\leq 0.001$ \\
\hline Whole grain breads, rice, pasta, pasties & 1.96 & 0.56 & $-71 \%$ & $\leq 0.001$ \\
\hline Whole grain cereals (incl. hot cereal) & 1.26 & 0.49 & $-61 \%$ & $\leq 0.001$ \\
\hline Popcorn and other whole grain snacks & 0.00 & 0.07 & & 0.005 \\
\hline Non-whole grain breads, rice, pasta & 3.08 & 6.06 & $97 \%$ & $\leq 0.001$ \\
\hline Dairy & 6.23 & 3.39 & $-46 \%$ & $\leq 0.001$ \\
\hline Whole milk, yogurt, and cream & 0.14 & 0.50 & $258 \%$ & $\leq 0.001$ \\
\hline Low-fat and skim milk and low-fat yogurt & 5.95 & 1.49 & $-75 \%$ & $\leq 0.001$ \\
\hline All cheese (incl. cheese soup and sauce) & 0.14 & 0.83 & $492 \%$ & $\leq 0.001$ \\
\hline Milk drinks and milk desserts & 0.00 & 0.58 & & $\leq 0.001$ \\
\hline Protein & 7.91 & 13.74 & $74 \%$ & $\leq 0.001$ \\
\hline Beef, pork, veal, lamb, and game & 1.40 & 3.63 & $159 \%$ & $\leq 0.001$ \\
\hline Chicken, turkey, and game birds & 3.29 & 5.44 & $65 \%$ & $\leq 0.001$ \\
\hline Fish and fish products & 1.19 & 2.31 & $94 \%$ & $\leq 0.001$ \\
\hline Bacon, sausages, and luncheon meats & 0.00 & 1.31 & & $\leq 0.001$ \\
\hline Nuts, nut butters, and seeds & 1.96 & 0.26 & $-87 \%$ & $\leq 0.001$ \\
\hline Egg and egg mixtures & 0.07 & 0.80 & $1,042 \%$ & $\leq 0.001$ \\
\hline Other foods & 2.38 & 9.17 & $285 \%$ & $\leq 0.001$ \\
\hline Table fats, oils, and salad dressings & 0.70 & 0.42 & $-40 \%$ & $\leq 0.001$ \\
\hline Gravies, sauces, condiments, and spices & 0.70 & 0.32 & $-54 \%$ & $\leq 0.001$ \\
\hline Coffee and tea & 0.14 & 0.83 & $493 \%$ & $\leq 0.001$ \\
\hline Soft drinks, sodas, fruit drinks, and ades & 0.00 & 1.07 & & $\leq 0.001$ \\
\hline Sugars, sweets, and candies & 0.00 & 0.81 & & $\leq 0.001$ \\
\hline Soups (ready-to-serve and condensed) & 0.84 & 2.42 & $188 \%$ & $\leq 0.001$ \\
\hline Soups (dry) & 0.00 & 0.00 & & 1.000 \\
\hline Frozen or refrigerated entrees & 0.00 & 3.29 & & $\leq 0.001$ \\
\hline Vegetables & 8.13 & 8.35 & $3 \%$ & 0.952 \\
\hline All potato products & 1.05 & 0.96 & $-8 \%$ & 0.343 \\
\hline Dark-green vegetables & 2.52 & 2.39 & $-5 \%$ & 0.534 \\
\hline Orange vegetables & 1.26 & 0.79 & $-37 \%$ & $\leq 0.001$ \\
\hline Canned and dry beans, lentils, and peas & 1.12 & 0.97 & $-13 \%$ & 0.097 \\
\hline Other vegetables & 2.38 & 3.24 & $36 \%$ & $\leq 0.001$ \\
\hline
\end{tabular}

${ }^{1}$ TFP $=$ Thrifty Food Plan.

The opposite was true for grains and the other foods category, where both spending and consumption exceeded TFP recommendations. For other foods, spending and consumption both greatly exceeded the TFP recommendations, by 285 and 305\%, respectively. For proteins and vegetables an inverse relationship exists between spending and the quantity consumed. Although our sample population spends $74 \%$ more of their budget on protein than the TFP recommends, they actually consumed 0.44 pounds or $10 \%$ less than what is recommended. Similarly, for the vegetable group, study participants reported spending slightly more $(3 \%)$ than the TFP recommendation, but consumed 34\% less vegetables by weight than recommended. 
Although spending on grains exceeded the TFP amount by $14 \%$, consumption exceeded the TFP recommendation by $91 \%$, due in large part by the high consumption of the non-whole grain breads, cereals, rice, pasta category. These disparities point to the relative costs of various food groups, particularly the high per calorie cost of fruits, vegetables, and meat, and the low cost per calorie of non-whole grains (Figure 2).

Table 3. Food consumption comparison, by food categories, for the Thrifty Food Plan (TFP) and low-income food assistance recipients, Santa Clara and San Mateo counties.

\begin{tabular}{|c|c|c|c|c|}
\hline Food category & $\begin{array}{l}\text { TFP suggested } \\
\text { consumption } \\
\text { (lbs.) / week }\end{array}$ & $\begin{array}{l}\text { *Adjusted } \\
\text { consumption } \\
\text { (lbs.) / week }\end{array}$ & $\begin{array}{l}\text { Difference between } \\
\text { actual and TFP } \\
\text { consumption }\end{array}$ & $P$-value \\
\hline Fruits & 5.62 & 4.50 & $-20 \%$ & $\leq 0.001$ \\
\hline Whole fruits & 5.16 & 3.20 & $-38 \%$ & $\leq 0.001$ \\
\hline Fruit juices & 0.46 & 1.30 & $183 \%$ & $\leq 0.001$ \\
\hline Grains & 2.77 & 5.29 & $91 \%$ & $\leq 0.001$ \\
\hline Whole grain breads, rice, pasta and pasties & 1.25 & 0.54 & $-57 \%$ & $\leq 0.001$ \\
\hline Whole grain cereals (incl. hot cereal) & 0.38 & 0.77 & $103 \%$ & $\leq 0.001$ \\
\hline Popcorn and other whole grain snacks & 0.00 & 0.01 & & 0.002 \\
\hline Non-whole grain breads, cereals, rice, pasta & 1.14 & 3.98 & $249 \%$ & $\leq 0.001$ \\
\hline Dairy & 11.54 & 4.02 & $-65 \%$ & $\leq 0.001$ \\
\hline Whole milk, yogurt, and cream & 0.20 & 0.62 & $209 \%$ & $\leq 0.001$ \\
\hline Low-fat and skim milk and low-fat yogurt & 11.31 & 2.86 & $-75 \%$ & $\leq 0.001$ \\
\hline All cheese (incl. cheese soup and sauce) & 0.03 & 0.19 & $547 \%$ & $\leq 0.001$ \\
\hline Milk drinks and milk desserts & 0.00 & 0.35 & & $\leq 0.001$ \\
\hline Protein & 4.28 & 3.84 & $-10 \%$ & $\leq 0.001$ \\
\hline Beef, pork, veal, lamb, and game & 0.65 & 0.91 & $40 \%$ & 0.001 \\
\hline Chicken, turkey, and game birds & 2.67 & 1.52 & $-43 \%$ & $\leq 0.001$ \\
\hline Fish and fish products & 0.43 & 0.46 & $8 \%$ & 0.679 \\
\hline Bacon, sausages, and luncheon meats & 0.00 & 0.33 & & $\leq 0.001$ \\
\hline Nuts, nut butters, and seeds & 0.47 & 0.11 & $-76 \%$ & $\leq 0.001$ \\
\hline Egg and egg mixtures & 0.06 & 0.50 & $737 \%$ & $\leq 0.001$ \\
\hline Other foods & 1.92 & 7.78 & $305 \%$ & $\leq 0.001$ \\
\hline Table fats, oils, and salad dressings & 0.55 & 0.19 & $-66 \%$ & $\leq 0.001$ \\
\hline Gravies, sauces, condiments, and spices & 0.55 & 0.18 & $-67 \%$ & $\leq 0.001$ \\
\hline Coffee and tea & 0.02 & 2.68 & $13,279 \%$ & $\leq 0.001$ \\
\hline Soft drinks, sodas, fruit drinks, and ades & 0.00 & 1.92 & & $\leq 0.001$ \\
\hline Sugars, sweets, and candies & 0.04 & 0.27 & $587 \%$ & $\leq 0.001$ \\
\hline Soups (ready-to-serve and condensed) & 0.76 & 1.46 & $92 \%$ & 0.005 \\
\hline Soups (dry) & 0.00 & 0.00 & & 1.000 \\
\hline Frozen or refrigerated entrees & 0.00 & 1.08 & & $\leq 0.001$ \\
\hline Vegetables & 7.40 & 4.70 & $-36 \%$ & $\leq 0.001$ \\
\hline All potato products & 2.05 & 0.78 & $-62 \%$ & $\leq 0.001$ \\
\hline Dark-green vegetables & 1.29 & 1.01 & $-22 \%$ & $\leq 0.001$ \\
\hline Orange vegetables & 1.19 & 0.47 & $-61 \%$ & $\leq 0.001$ \\
\hline Canned and dry beans, lentils, and peas & 0.93 & 0.72 & $-22 \%$ & $\leq 0.001$ \\
\hline Other vegetables & 1.94 & 1.73 & $-11 \%$ & $\leq 0.001$ \\
\hline
\end{tabular}




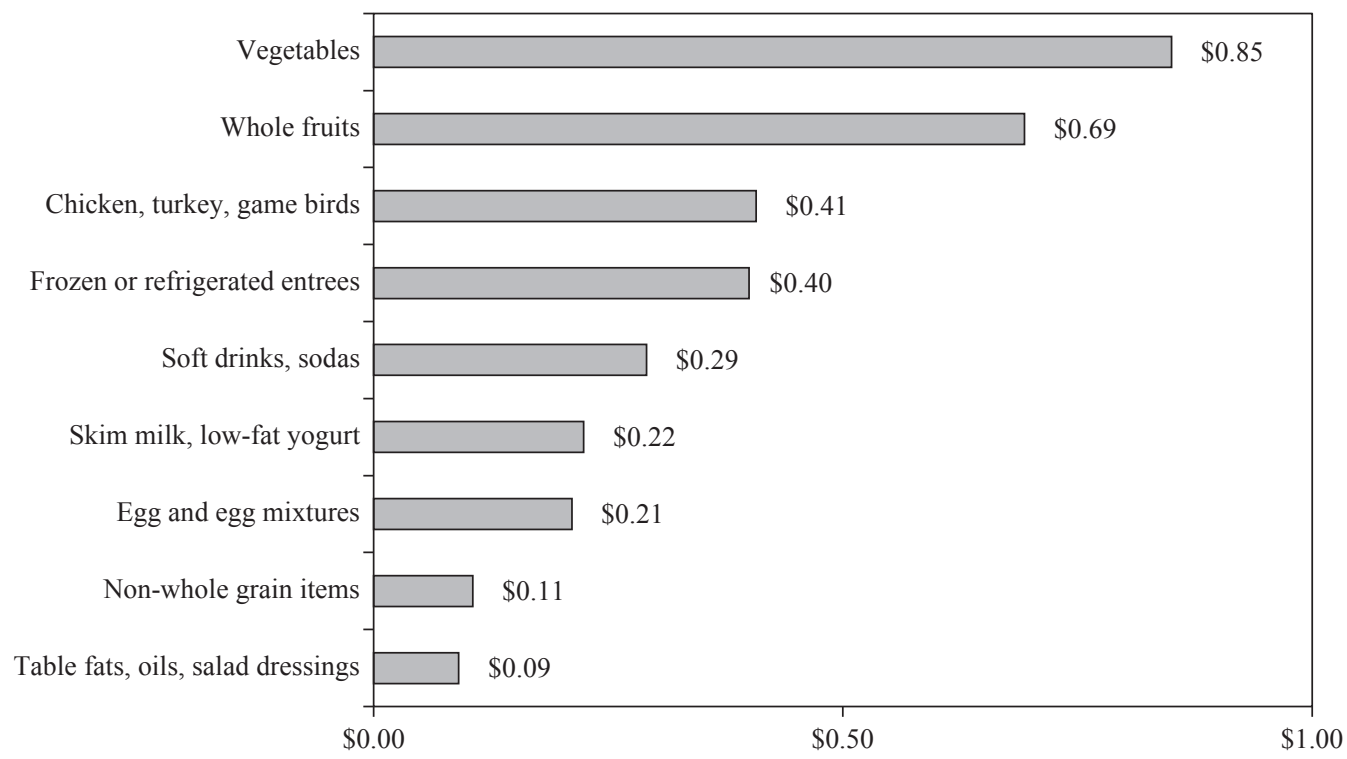

Figure 2. Cost per 100 calories for various food categories and subcategories calculated based on survey respondents' actual food prices.

\section{Discussion}

Based on the actual spending and consumption habits of food bank clients in Silicon Valley, it appears that this group of low-income families is struggling to consume a low-cost and nutritious diet as laid out in the TFP. In our study, food bank clients spent $27 \%$ more than what the TFP suggests is needed for a healthy diet, but were eating less food than the TFP suggested, particularly in the fruit, vegetable, protein, and dairy categories. The typical food bank client in our study was spending $\$ 10.28$ more, but eating 3.40 pounds less than the weekly TFP recommendations. Our results, which are regionally specific, show expenditure levels higher than a national simulation, which found that low-income households spend about $86 \%$ of the TFP on food (Steward and Blisard, 2006). This discrepancy may be due in part to geographic variation in food prices; according to Todd et al. (2011) food prices in Metro California are nearly $112 \%$ of the national averages. Our findings are more similar to a study of low-income women in California, which also used local food prices, and calculated a mean daily diet cost of $\$ 6.11$ (Townsend et al., 2009). Moreover, the total daily adjusted food cost of $\$ 6.87$ for SHFB clients does not include other important resources needed to obtain and prepare healthy at-home meals because it does not include the value of time (IOM/NRC, 2013). Time is recognized as an important consideration for households at all income levels, and particularly for working parents. Davis and You (2011) found that financial resources account for $60 \%$ of the resources needed for the TFP and that time accounts for $40 \%$. Using this ratio, SFHB clients could be expending the equivalent of an additional $\$ 4$ to $\$ 5$ per day when the value of their time is taken into consideration.

SHFB clients spent close to the TFP recommended levels on fruits and vegetables, but overspent on protein and other foods. Other studies have found strong cultural and personal preferences for protein among low-income consumers (Alkon et al., 2013; Askelson et al., 2018). Wiig and Smith (2009) found that lowincome urban mothers prioritized purchasing meat and allocated the largest portion of their food budget for meat, based on taste preference and because it was a versatile and filling component of meals. Given that expenditures on meat and eggs make up the largest portion of SHFB clients' food budgets, a similar dynamic may be at work in our study area.

The allocation of foods consumed reveals that SHFB clients are eating less of food groups that are recommended for a healthy diet, such as whole fruits $(-38 \%)$, whole grains $(-57 \%)$, and vegetables $(-36 \%)$. Although the majority of U.S. consumers eat less than the recommended quantities of fruits and vegetables, studies have 
shown that low-income households eat even fewer fruits and vegetables than their high-income counterparts (Bazerghi et al., 2016; Gosliner et al., 2018; Stewart and Blisard, 2006). Qualitative studies of low-income consumers show the confluence of household and environmental factors that can affect decisions about fruit and vegetable consumption. While low-income consumers appreciate the nutritional value of fruits and vegetables, they often cite high prices as a barrier to greater consumption (Askelson et al., 2018; Wiig and Smith, 2009). Figure 2 illustrates the relative cost of several food categories with vegetables and fruits exhibiting a much higher cost per 100 calories than other more filling foods, such as chicken, eggs, and non-whole grains. Moreover, infrequent shopping trips, which may occur because of the difficulty or cost of transportation, make it difficult to make fresh fruits and vegetables a routine part of meals because of their perishability (Askelson et al., 2018). Instead, when money was tight, low-income consumers preferred to purchase items that lasted longer than produce and which helped to stretch meals, such as meat, dairy, grains, and processed foods.

The largest discrepancy between the TFP recommended budget and consumption allocation and spending and consumption among food bank clients was in the other food group. Within this group, the biggest difference between actual behavior and TFP recommendations was for frozen and refrigerated entrees and ready-to-serve soups. There are no TFP allocations for these subcategories, but interviewees spent approximately $12 \%$ of their food budget on these items. In this case, time, cooking space, and cold storage space are likely to be important limiting factors. For single parents or people working multiple jobs, there may not be enough time for shopping, price comparison, and meal preparation. We discussed the apparent paradox of high expenditures on "convenience" foods among a low-income population with a limited food budget with the SHFB staff. Site coordinators indicated that because of the extremely high cost of living in the Bay Area, low-income families frequently have non-traditional living situations. Often, multiple families reside in a single-family house, condominium, or apartment, and must share a single kitchen. In these cases, each family may have access to one shelf in the refrigerator, limited pantry space, and a short period of time to prepare a meal. Thus, frozen or refrigerated entrees or other highly processed foods, which can be prepared in a short amount of time, are a solution to their limited access to food storage and cooking facilities. In Toronto, Kirkpatrick and Tarusk (2011) also found that low-income families may choose to live together to save money. More significantly, they found that after-housing income was inversely related to food insecurity. We expect that in the high-cost Silicon Valley region, housing costs and the compromises that low-income families make in their living situations play an outsized role in the financial and physical resources they have for food and meal preparation. Additional qualitative research is needed to illuminate the relationship between housing costs, food security, and diet quality in Silicon Valley and other high-cost regions.

\subsection{Limitations}

Our results have several limitations. First, the sample was not randomly selected. Instead, we purposely selected food bank distribution sites to ensure that our sample represented a broad swath of ethnic and age groups. Because we relied on a convenience sample, our sample may differ from the population of SHFB bank recipients as well as regional and national populations with respect to age, gender, income, ethnicity and other factors. Second, the research was conducted in a high-cost metropolitan area that may not be representative of other parts of the U.S. The results are more likely to apply to food-insecure populations in other high-cost metropolitan areas. Third, most of the clients receiving food assistance at the sites we surveyed were female. Thus, the expenditures and consumption patterns we report may be more representative of women's than men's diets. Finally, in this study, we used the single-pass, 24-hour dietary recall. Thus, although the single pass dietary recall survey has been shown to be adequate for estimating mean intakes for a large group (Gibson, 2005), it does not capture fluctuations in food consumption from day to day, which could influence our results. 


\section{Concluding remarks}

We found that the low-income people we surveyed spent substantially more on food than the TFP suggests, while consuming less than recommended amount of fruits and vegetables, dairy, and protein. These results suggest that the current TFP may not adequately reflect a practical, low-cost, healthy and nutritious diet as noted by Mulik and Haynes-Maslow (2017). This is particularly true for individuals living in high-cost areas who have to make difficult decisions when paying for food, housing, medical care, and other basic necessities with limited resources (Fiese et al., 2014).

Our findings suggest that food insecure populations could benefit from changing the way that the TFP is calculated. Specifically, accounting for the cost of food in high-cost areas would go a long way towards addressing the food budget shortfalls experienced by many food insecure people. More generally, examining whether a national TFP, including both cost and food category components makes sense for a diverse population with greatly different food habits, consumption patterns, and costs could lead to the identification of opportunities to make the TFP better suited for local communities. Our results also suggest that consideration should be given to the unique challenges faced by food insecure families. Transportation costs, limited food storage space, access to kitchen facilities, and the value of the food preparer's time all influence the type of foods purchased and the full cost of food. Addressing these issues would result in more realistic food budgets that reflect the circumstances of people receiving food assistance, particularly in high-cost areas.

Another major finding of this study is the underspending and underconsumption of fruits and vegetables by food bank clients. This is not unique as reported in research by Bazerghi et al. (2016), Gosliner et al. (2018), and Stewart and Blisard (2006). Furthermore, given the high per calorie cost of fruits and vegetables, changes in model food budgets are unlikely to result in improved diets among the low-income population.

There are several policy options that might be explored to encourage better nutrition and more balanced diets among food insecure populations. Some examples are, ensuring access to affordable fruits and vegetables in low-income neighborhoods through zoning or subsidized grocery offerings and the pilot program to provide financial incentives to SNAP participants through fruit and vegetable vouchers. Another opportunity is to encourage and promote participation in urban and school gardens, which would both increase access to fresh fruits and vegetables as well as encourage improved nutritional habits, especially among children.

Food banks and their partners should also consider the frequency of food distribution to their clients. In the case of the SHFB's FH program, food is distributed once a month. Because most fruits and vegetables have a shelf life of much less than one month, the produce received from SHFB will be gone long before the end of the month. More frequent distribution of fresh produce, such as twice monthly, may encourage more frequent consumption of produce and increase the amount consumed by families. Our partner in this study, the SHFB of Santa Clara and San Mateo Counties, has worked to increase fresh produce consumption by ensuring that at least $50 \%$ of the food they distribute is fresh produce. Still they find it difficult to economically source enough produce to meet demand. Another opportunity for SHFB and other food banks is to examine alternative and underutilized sources of fresh produce. One such promising opportunity is to work to develop programs to economically harvest and pack edible food left unharvested in the field (Baker et al., 2019; Johnson et al., 2018).

It is also noteworthy that a high (62.8\%) percentage of participants in our study were born outside of the U.S. Similarly, a high percentage of respondents were not receiving government food assistance (67.5\%). Because we did not inquire as to respondents' immigration status, we do not know to what extent this impacted decisions to receive assistance from the food bank but not the government. Nonetheless, anecdotal evidence based on conversations with food bank clients and food bank employees lead us to believe that clients' concerns regarding the possible consequences of receiving government assistance, even among those who hold permanent residency or citizenship, dissuade them from applying for government benefits. This suggests an educational role for food banks and the possibility of better outreach among government agencies to ensure that those eligible for benefits apply and receive them. 
Much additional research is needed to understand questions raised by this study. We need to better understand how the characteristics and circumstances of different food insecure populations, as affected by factors such as region, ethnicity, access to grocery stores, etc. affect their needs and the ability to secure a healthy and nutritious diet. Another question is why food assistance recipients spend much more than the TFP, especially in high cost areas. Is it possible to stay within the budget allocation? Could people make alternative choices or select stores with less expensive food? What is the role of government and food banks in helping food insecure people improve their diets with their limited resources.

\section{Acknowledgements}

We extend our sincerest gratitude to the staff of Second Harvest of Silicon Valley, formerly Second Harvest of Santa Clara and San Mateo Counties. They provided the inspiration for the research and invaluable support in designing the study, providing access to their clients, and interpreting the results. We acknowledge the financial support received from the Bank of America Charitable Foundation. We also acknowledge the staff and researchers who contributed to the research, without whom the project would not have been possible, especially Erika French-Arnold.

\section{References}

Alkon, A.H., D. Block, K. Moore, C. Gillis, N. DiNuccio and N. Chavez. 2013. Foodways of the urban poor. Geoforum 48: 126-135.

Askelson, N.M., C. Meier, B. Baquero, J. Friberg, D. Montgomery and C. Hradek. 2018. Understanding the process of prioritizing fruit and vegetable purchases in families with low incomes: a peach may not fill you up as much as hamburger. Health Education \& Behavior 45(5): 817-823.

Babb, A.M., D.C. Knudsen, S.M. Robeson. 2019. A critique of the objective function utilized in calculating the Thrifty Food Plan. PLoS ONE 14(7): e0219895. https://doi.org/10.1371/journal.pone.0219895

Baker, G.A., L.C. Gray, M.J. Harwood, T.J. Osland and J.B.C. Tooley. 2019. On-farm food loss in northern and central California: results of field survey measurements. Resources, Conservation and Recycling 149: 541-549. https://doi.org/10.1016/j.resconrec.2019.03.022

Bazerghi, C., F.H. McKay and M. Dunn. 2016. The role of food banks in addressing food insecurity: a systematic review. Journal of Community Health 41(4): 732-740.

Bomkamp, S. 2016. Feeding American stretches goals under new leadership. Chicago Tribune. Available at: https://tinyurl.com/yd48cuvu

Bronchetti, E., G. Christensen and B. Hansen. 2016. Variation in food prices and SNAP adequacy for purchasing the Thrifty Food Plan. University of Kentucky Center for Poverty Research, Lexington, KY, USA.

Clawson, A., M. Lino, W.-Y. Juan, K. Hanson and Basiotis. 2007. Thrifty Food Plan, 2006. United States Department of Agriculture, Center for Nutrition Policy and Promotion, Washington, DC, USA.

Coleman-Jensen, A., M.P. Rabbitt, C.A. Gregory and A. Singh. 2018. Household food security in the United States in 2017. Research Report No. 256. United States Department of Agriculture, Economic Research Service, Washington, DC, USA.

Davis, G.C. and W. You. 2010. The Thrifty Food Plan is not thrifty when labor cost is considered. The Journal of Nutrition 140(4): 101-107. https://doi.org/10.3945/jn.109.119594

Davis, G.C. and W. You. 2011. Not enough money or not enough time to satisfy the Thrifty Food Plan? A cost difference approach for estimating a money-time threshold. Food Policy 36(2): 101-107.

Drewnowski, A. and P. Eichelsdoerfer. 2010. Can low-income Americans afford a healthy diet? Nutrition Today 44(6): 246.

Feeding America. 2011. Food banks: hunger's new staple. Research brief. Available at: https://tinyurl.com/ y7osymwe

Feeding America. Hunger in America 2014. Available at: https://tinyurl.com/yd3qlvx2

Fiese, B.H., B. Davis Koester and E. Waxman. 2014. Balancing household needs: the non-food needs of food pantry clients and their implications for program planning. Journal of Family and Economic Issues 35(3): 423-431. 
Gibson, R.S. 2005. Principles of nutritional assessment. Oxford University Press, New York, NY, USA.

Godwin, S. and E. Chambers IV. 2000. Cognitive issues and strategies of portion-size estimation and use in dietary studies. Journal of American Dietetic Association 100(8): 891-897.

Gosliner, W., D.M. Brown, B.C. Sun, G. Woodward-Lopez and P.B. Crawford. 2018. Availability, quality and price of produce in low-income neighbourhood food stores in California raise equity issues. Public Health Nutrition 21(9): 1639-1648.

Institute of Medicine / National Research Council (IOM/NRC). 2013. Supplemental nutrition assistance program: examining the evidence to define benefit adequacy. National Academies Press, Washington, DC, USA.

Johnson, L.K., R.D. Duning, J.D. Bloom, C.C. Gunter, M.D. Boyette and N.G. Creamer. 2018. Estimating on-farm food loss at the field level: a methodology and applied case study on a North Carolina farm. Resources, Conservation and Recycling 137: 243-250. https://doi.org/10.1016/j.resconrec.2018.05.017

Kirkpatrick, S.I. and V. Tarasuk. Housing circumstances are associated with household food access among low-income urban families. Journal of Urban Health 88(2): 284-296.

Mulik, K. and L. Haynes-Maslow. 2017. The affordability of MyPlate: an analysis of SNAP benefits and the actual cost of eating according to the dietary guidelines. Journal of Nutrition Education and Behavior 49(8): 623-631.

Nestle, M. 2012. Why calories count: the problem with dietary intake studies. The Atlantic. Available at: https://tinyurl.com/7409oqw

Oliveira, V. 2018. The food assistance landscape: FY 2017 annual report. USDA, ERS, Washington, DC, USA.

Page, E.T., E. Larimore, J.A. Kirlin and M. Denbaly. 2019. The national household food acquisition and purchase survey: innovations and research insights. Applied Economic Perspective and Policy 41(4): 215-234. https://doi.org/10.1093/aepp/ppy034

Powers, E.T. and N.J. Powers. 2001. The size and frequency of price changes: evidence from grocery stores. Review of Industrial Organization 18(4): 397-416.

Simmonds, C. 2017. The Silicon Valley paradox: one in four people are at risk of hunger. The Guardian, December 12. Available at: https://tinyurl.com/yb355u89

Stewart, H. and N. Blisard. 2006. The Thrifty Food Plan and low-income households in the United States: what food groups are being neglected? Food Policy 31(5): 469-482.

Todd, J., E. Leibtag and C. Penberthy. 2011. Geographic differences in the relative price of healthy foods. EIB-78. USDA, ERS, Washington, DC. Available at: https://tinyurl.com/yazqp89x

Townsend, M.S., G.J. Aaron, P. Monsivais, N.L. Keim and A. Drewnowski. 2009. Less-energy-dense diets of low-income women in California are associated with higher energy-adjusted diet costs. The American Journal of Clinical Nutrition 89(4): 1220-1226.

U.S. Census Bureau. n.d. Selected characteristics of people at specified levels of poverty in the past 12 months 2013-2017. Available at: https://factfinder.census.gov/

U.S. Department of Agriculture, Economic Research Service (USDA ERS). 2017. Definition of food security. USDA, ERS, Washington, DC, USA. Available at: https://tinyurl.com/yyhqguq5

U.S. Department of Agriculture, Food and Nutrition Service (USDA FNS). 2018. Supplemental nutrition assistance program (SNAP). Available at: https://tinyurl.com/17g2he2

U.S. Department of Health \& Human Services (HHS). 2014. 2014 poverty guidelines. HHS, Washington, DC, USA. Available at: https://aspe.hhs.gov/2014-poverty-guidelines\#tresholds

U.S. Department of Housing and Urban Development (HUD). 2018. Income limits. HUD, Washington, DC, USA. Available at: https://www.huduser.gov/portal/datasets/il.html

Weber, B. 2017. Silicon Valley wages can't keep up with housing prices: report. NBC Bay Area, July 18. Available at: https://tinyurl.com/y7onedxf

Wiig, K. and C. Smith. 2009. The art of grocery shopping on a food stamp budget: factors influencing the food choices of low-income women as they try to make ends meet. Public Health Nutrition 12(10): 1726-1734.

Wilde, P.E. and J. Llobrera. 2009. Using the Thrifty Food Plan to assess the cost of a nutritious diet. Journal of Consumer Affairs 43(2): 274-304. https://doi.org/10.1111/j.1745-6606.2009.01140.x 